\title{
Acute Otitis Media in Childhood - Use of Guidelines for Diagnosis and Treatment in Emergency Rooms
}

\author{
Eduardo Jorge da Fonseca Lima ${ }^{1,}$, Fernanda Zeilmann Cazzetta ${ }^{2}$, \\ Maria Eduarda de Araújo Cabral ${ }^{2}$, Caroline Cordeiro de Andrade ${ }^{2}$, \\ Pedro Jorge Serra da Fonseca Lima ${ }^{2}$, Patrícia Gomes de Matos Bezerra ${ }^{3}$ \\ ${ }^{1}$ Departament of the Lato Sensu Postgraduate Course of Instituto de Medicina Integral Prof. Fernando Figueira (IMIP) and Department of \\ Graduation of Faculdade Pernambucana de Saúde (FPS), Recife, Brazil \\ ${ }^{2}$ Department of Graduation of Faculdade, Pernambucana de Saúde (FPS), Recife, Brazil \\ ${ }^{3}$ Departament of Pediatric Pulmonology of Instituto de Medicina Integral Prof. Fernando Figueira (IMIP) and Department of Graduation of \\ Faculdade Pernambucana de Saúde (FPS), Recife, Brazil
}

\section{Email address:}

eduardojorge@imip.org.br (E. J. da F. Lima)

${ }^{*}$ Corresponding author

\section{To cite this article:}

Eduardo Jorge da Fonseca Lima, Fernanda Zeilmann Cazzetta, Maria Eduarda de Araújo Cabral, Caroline Cordeiro de Andrade, Pedro Jorge Serra da Fonseca Lima, Patrícia Gomes de Matos Bezerra. Acute Otitis Media in Childhood - Use of Guidelines for Diagnosis and Treatment in Emergency Rooms. American Journal of Pediatrics. Vol. 5, No. 3, 2019, pp. 91-97. doi: 10.11648/j.ajp.20190503.13

Received: May 22, 2019; Accepted: June 24, 2019; Published: July 4, 2019

\begin{abstract}
Background: AOM is characterized by its high prevalence and morbidity but low lethality. It is estimated that $70 \%$ of children will have had one episode prior to completing five years of age Compliance with the guidelines for acute otitis media (AOM) may avoid complications. This study aimed at determining whether pediatricians follow the guidelines for AOM management. Methods: A prospective, cross-sectional study involving pediatricians working in emergency centers in Recife. A specific questionnaire was used to collect data. Results: Of the 71 pediatrics interviewed around $98 \%$ gave importance to crying/irritability and otalgia when diagnosing otitis and all recognized the significance of otorrhoea. All the professionals gave importance to bulging tympanic membrane, $98.6 \%$ to acute tympanic membrane perforation, $97.1 \%$ to purulent effusion and $46.5 \%$ to bilateral hyperemia of the tympanic membrane. Regarding antibiotic therapy, $70.4 \%$ used standard doses of amoxicillin as first-line treatment ( $81.7 \%$ prescribing for 10 days). Furthermore only $47.9 \%$ double the dose in case of therapeutic failure. Conclusion: Pediatricians working in emergency departments need to be better informed about the guidelines to decrease inappropriate prescription of antibiotics for AOM. We believe that adoption of the "wait and see" strategy, even in emergency rooms, would be an important means of reducing the inadequate prescription of antibiotics in cases of AOM, thus contributing towards reducing bacterial resistance.
\end{abstract}

Keywords: Acute Otitis Media, Paediatrics, Guidelines, Diagnosis, Treatment

\section{Introduction}

Acute otitis media (AOM) is an inflammation of the middle ear mucosa. It is generally associated with the rapid onset of signs and symptoms of an acute middle ear infection, involving fever, otalgia and irritability. AOM is often secondary to an upper respiratory tract infection. [1] The World Health Organization estimates that 51,000 deaths occur annually in children under five years of age as a result of AOM complications. [2]
AOM is characterized by its high prevalence and morbidity but low lethality. It is estimated that $70 \%$ of children will have had one episode prior to completing five years of age. [3-4] In a cohort study, $71 \%$ of the children evaluated had had one or more episodes of AOM prior to completing three years of age, with the condition being more prevalent in boys. [5] In general, the disease affects infants in the first two years of life, with a major incidence peak at 6-11 
months and a secondary peak at 4-5 years of age. The low incidence in children up to six months of age is explained by the presence of transplacental antibodies, less exposure to pathogens and the position used for breastfeeding. [6] Socialization in schools and day-care centres is the factor that most contributes to the occurrence of AOM, [7] particularly because the children share enclosed spaces as well as accessories such as feeding bottles and pacifiers, perpetuating a recurrent cycle of upper respiratory tract infections. The risk of recurrence appears to be associated with the age at which the first episode appears: $60 \%$ of children with a recurrence during childhood had their first episode prior to completing six months of age. [8]

The precise diagnosis of AOM in infants and small children can be difficult. Symptoms may be mild or may overlap those of an upper respiratory tract infection. [9] Visualization and analysis of alterations in the tympanic membrane may also be hampered by the presence of wax in the ear canal. [8-9]

Other factors that make an accurate diagnosis difficult include the child's lack of cooperation during evaluation, a lack of adequate equipment such as a pneumatic otoscope, a lack of training and inappropriate instruments with which to clean the ear canal. [8-9] Physicians need to be trained to make the differential diagnosis between AOM and otitis media with effusion, which is defined by the presence of fluid in the middle ear, with no signs or symptoms of acute infection. This is a relevant factor in the inappropriate prescription of antibiotics, consequently leading to an increase in the occurrence of adverse events and in the development of bacterial resistance. [10-12]

There is evidence that some physicians are resistant to complying with the diagnostic criteria proposed in standardized guidelines, suggesting that the information contained therein needs to be disseminated and its recommendations implemented to ensure the effective diagnosis and treatment of AOM, thus avoiding possible complications resulting from the infection. [13-17]

The accurate diagnosis of AOM is a controversial subject in medical practice. [9, 18-23] Laine et al. [23] evaluated children whose parents suspected that their child had AOM. The diagnosis was confirmed by tympanic-membrane examination in around half the children, while the other half actually had other problems of the upper respiratory tract. In relation to the symptoms used as criteria for a diagnosis of AOM, other studies [19-21] showed that otalgia is the symptom considered most relevant despite being present in only $50-60 \%$ of children.

At the end of the previous century the recommendation was to prescribe antibiotics at the time of diagnosis of AOM to minimize the risk of complications. Nevertheless, since 2004 and with the update in 2013 the American Academy of Paediatrics (AAP) guidelines [24] recognize that in cases of AOM with no complications antibiotic treatment may be unnecessary and recommend monitoring these patients and prescribing only analgesics. On the other hand, Coco et al. [15] conducted a study between 2002 and 2006 in outpatient clinics in the United States and reported that the rate of antibiotic prescription remained unchanged following publication of the clinical guideline in 2004, with the only difference being an increase in the prescription of amoxicillin and analgesics and a reduction in the prescription of amoxicillin/ clavulanate.

Considering the importance of otitis, the difficulties involved in appropriately diagnosing and treating the condition, and the few studies carried out in Brazil to evaluate the correct management of this disease, the objective of the present study was to evaluate paediatricians' compliance with the principal international and national guidelines on the management of AOM.

\section{Methods}

This was a cross-sectional cohort study conducted in the paediatric emergency department of the Instituto de Medicina Integral Prof, Fernando Figueira (IMIP), which provides healthcare to patients within the Brazilian National Health Service (Sistema Único de Saúde - SUS), and in the emergency rooms of two private hospitals: the Hospital Esperança and the Hospital Real Português. The convenience sample included duty doctors and medical residents. Data were collected at the study sites between November 2014 and April 2015.

The protocol of this study was approved by the internal review board of the Faculdade Pernambucana de Saúde under reference number 909.899 . The study was conducted in accordance with the relevant ethical guidelines governing research in human beings. All participants signed an informed consent form. Participants' identity was strictly protected throughout the study and their anonymity will continue to be preserved afterwards.

The clinical variables evaluated with respect to their importance in the diagnosis of AOM were: fever, a runny nose/cough, crying/irritability, associated rhinitis, vomiting associated with fever, otalgia, and otorrhoea. The weight given to the use of conventional or pneumatic otoscopy in the examination was recorded. The otoscopic findings evaluated for their importance were: unilateral/ bilateral hyperaemia, opacity, bulging, perforation and retraction of the tympanic membrane; the presence of purulent effusion; and nonvisualization of the auditory ossicles.

The variables related to treatment were: the use of antibiotics, the drug used (standard dose of amoxicillin 40-50 $\mathrm{mg} / \mathrm{kg} / \mathrm{day} ;$ double dose of amoxicillin 90 $\mathrm{mg} / \mathrm{kg} /$ day; standard dose of amoxicillin plus clavulanate; double dose of amoxicillin 80-100 $\mathrm{mg} / \mathrm{kg} /$ day plus clavulanate; cefaclor; ceftriaxone; cephalexin; clarithromycin; clindamycin), predicted duration of antibiotic use, need for re-evaluation, and the number of days between the implementation of antibiotic therapy and the recommended clinical re-evaluation. The use of symptomatic treatment such as oral corticoids, decongestants, and analgesics was also evaluated.

When the participants returned their completed form, 
they were recorded in a registration log. Next, a database was constructed, with data entry being performed in duplicate to ensure that any errors or inconsistencies would be corrected.

The STATA/SE software package, version 12.0, and Excel 2010 were used for data analysis. Significance level was established at $95 \%$. Tables of absolute and relative frequency were constructed. For the categorical variables, Fisher's exact test was used to verify the existence of association and, when necessary, the chi-square test was used, with p-values $<0.05$ being considered statistically significant.

\section{Results}

The sample consisted of 71 paediatricians working at public and private emergency departments in three hospitals in the city of Recife. The characteristics of the sample are shown in Table 1. Fifty-eight of the paediatricians in the sample $(81.7 \%)$ were female. More than half were over 35 years of age and 44 participants $(62 \%)$ had been working as a paediatrician for at least five years at the time of the study.

Table 1. Sociodemographic characterization of the paediatricians Knowledge, Attitude and Practice in managing acute otitis media. Recife, Brazil, 2015.

\begin{tabular}{lll}
\hline Characteristics & $\mathbf{n}$ & $\mathbf{\%}$ \\
\hline Sex & & \\
\hline Female & 58 & 81.7 \\
Male & 13 & 18.3 \\
Age * & & \\
24-29 years & 19 & 26.7 \\
30-35 years & 13 & 18.3 \\
$>$ 35 years & 37 & 52.1 \\
Time in the specialty & & \\
$\leq 5$ years & 27 & 38.0 \\
$>$ 5 years & 44 & 62.0 \\
Specialist degree & & \\
Yes & 31 & 43.6 \\
No & 35 & 49.3 \\
Place of employment & & \\
Public service & 35 & 49.3 \\
Private service & 36 & 50.7 \\
\hline
\end{tabular}

* data missing in two cases

Table 2 describes the signs, symptoms and otoscopic findings used by the paediatricians in the emergency rooms to diagnose otitis. When diagnosing otitis, the vast majority gave importance to the presence of crying/irritability (98.6\%) and otalgia (97.2\%), and all gave weight to the presence of otorrhoea. With respect to the otoscopic findings, 71 professionals $(100 \%)$ gave importance to tympanic membrane bulging, while 70 (98.6\%) gave importance to acute tympanic membrane perforation and $69(97.1 \%)$ took the presence of a purulent effusion into consideration. Nevertheless, only 33 professionals $(46.5 \%)$ gave importance to bilateral hyperaemia of the tympanic membrane, while $40(56.3 \%)$ took unilateral hyperaemia into consideration.
Table 2. Importance given by the paediatricians to the signs, symptoms and otoscopic findings for a diagnosis of acute otitis media. Recife, Brazil, 2015.

\begin{tabular}{lll}
\hline Factors considered important & $\mathbf{n}$ & $\mathbf{\%}$ \\
\hline Clinical data & & \\
\hline Otorrhoea & 71 & 100.0 \\
Crying/irritability & 70 & 98.6 \\
Otalgia & 69 & 97.2 \\
Fever & 55 & 77.5 \\
Associated rhinitis & 51 & 71.8 \\
Runny nose/cough & 49 & 69.0 \\
Vomiting associated with fever & 41 & 57.7 \\
Otoscopic Findings & & \\
Tympanic membrane bulging & 71 & 100.0 \\
Acute tympanic membrane perforation & 70 & 98.6 \\
Purulent effusion & 69 & 97.2 \\
Opacity of the tympanic membrane & 61 & 85.9 \\
Auditory ossicles not visualized & 54 & 76.0 \\
Tympanic membrane retraction & 53 & 77.9 \\
Unilateral hyperaemia of the tympanic membrane & 40 & 56.3 \\
Bilateral hyperaemia of the tympanic membrane & 33 & 46.5 \\
\hline
\end{tabular}

These professionals' first choice of antibiotic for the management of otitis is shown in Table 3.

Table 3. Therapeutic management of acute otitis media as reported by the paediatricians. Recife, Brazil, 2015.

\begin{tabular}{lll}
\hline Condition management & n & \% \\
\hline Drug initially used for the treatment of otitis & & \\
Amoxicillin - standard dose & 50 & 70.4 \\
Amoxicillin - standard dose plus clavulanate & 15 & 21.1 \\
Amoxicillin - double the standard dose & 6 & 8.5 \\
Period of use of the first drug & & \\
S5 days & 3 & 4.2 \\
6-8 days & 6 & 8.5 \\
9-10 days & 58 & 81.7 \\
>10 days & 4 & 5.6 \\
Recommends re-evaluation & & \\
Yes & 64 & 90.1 \\
No & 7 & 9.9 \\
Re-evaluation (days) & & \\
2 days & 14 & 19.7 \\
3-5 days & 36 & 50.7 \\
6-10 days & 9 & 12.6 \\
> 10 days & 5 & 7.0 \\
Did not answer & 7 & 9.8 \\
Drug used as second option for the treatment of otitis & & \\
Amoxicillin - double the standard dose & 34 & 47.9 \\
Amoxicillin - standard dose plus clavulanate & 16 & 22.5 \\
Amoxicillin - double the standard dose plus clavulanate & 9 & 12.7 \\
Amoxicillin - standard dose & 4 & 5.6 \\
Cefaclor & 1 & 1.4 \\
Did not answer & 7 & 9.8 \\
Drug most commonly used in cases of no response to first- & & \\
line therapy & & \\
Amoxicillin - double the standard dose & 29 & 40.8 \\
Amoxicillin - double the standard dose plus clavulanate & 17 & 23.9 \\
Amoxicillin - standard dose plus clavulanate & 12 & 16.9 \\
Did not answer & 13 & 18.3 \\
Recommends use of oral corticoids & & \\
Yes & 9 & 12.6 \\
No & 59 & 83.0 \\
Did not answer & 3 & 4.2 \\
Recommends use of systemic decongestant & & \\
Yes & 5 & 7.0 \\
No & 66 & 93.0 \\
Recommends use of analgesic & & \\
\hline & &
\end{tabular}




\begin{tabular}{lll}
\hline Condition management & n & $\mathbf{\%}$ \\
\hline Yes & 69 & 97.2 \\
No & 1 & 1.4 \\
Did not answer & 1 & 1.4 \\
\hline
\end{tabular}

Around $70 \%$ of the paediatricians $(n=50)$ reported that they used amoxicillin at the standard dose as first-line treatment. In relation to the duration of treatment, 58 paediatricians $(81.7 \%)$ prescribed a 10-day course of antibiotics, with only 3 professionals $(4.2 \%)$ routinely prescribing a 5-day course. Sixty-four paediatricians (around $90 \%$ ) recommended clinical re-evaluation after treatment had been instituted, with $50.7 \%$ of physicians stating that reevaluation should take place after 3-5 days.

Regarding the antibiotic prescribed in cases of treatment failure, the answers given were: amoxicillin at double the standard dose (34 professionals; 47.9\%), amoxicillin at double the standard dose plus clavulanate (16 paediatricians; $22.5 \%$ ) and amoxicillin at the standard dose plus clavulanate (9 professionals; $12.7 \%$ ).

Only 9 doctors $(12.6 \%)$ prescribed symptomatic treatment with corticoids, while $5(7 \%)$ prescribed systemic decongestants. The vast majority (69 physicians; 97.2\%) routinely prescribed analgesics.

\section{Discussion}

The AAP published its guidelines for the diagnosis and treatment of AOM with the objective of helping primary care physicians manage the disease. [24] The aim of the present study was to determine whether the clinical data taken into consideration by physicians when attending their patients and the treatment they prescribe are indeed in compliance with those guidelines.

The number of women in medicine today and particularly in paediatrics has already been reported in other studies, [2528] and was confirmed in the sample of participants in the present study in which $81.7 \%$ of the 71 participants were female. The fact that $62 \%$ of the participants had been working as paediatricians for at least five years suggests that the interviewees in this study were experienced in managing the principal emergencies. AOM is the principal reason for prescribing antibiotics to outpatients, [29] and it is very probable that these emergency room doctors had already had to deal with various cases of AOM. Nevertheless, in the emergency department at IMIP, data were collected not only from duty doctors but also from medical residents, and this may explain the percentage of participants with less than five years' experience in the specialty.

Nonspecific clinical data such as crying, irritability and otalgia continue to be considered highly important by paediatricians. These data are also referred to in the AAP guidelines, which address the presence of earache or a child's nonverbal act of holding, pulling or rubbing his/her ear as part of the diagnosis. This finding partially contradicts other reports, [21-23] which have shown that earache is present in only $50-60 \%$ of children with AOM.

Otorrhoea is the final stage in the evolution of AOM and its presence was taken into consideration by all the paediatricians, emphasizing the significance of this symptom. This is in agreement with the AAP guidelines that a diagnosis of AOM should not be made without a finding of middle ear effusion at pneumatic otoscopy. Nevertheless, in the present study, only one physician mentioned the importance of pneumatic otoscopy. All the guidelines emphasize the importance of well conducted otoscopy in the diagnosis of AOM. [10, 24] In the present study, tympanic membrane bulging and the presence of a purulent effusion in the ear canal were the factors given most importance by the participants in diagnosing otitis. One of the principal diagnostic criteria proposed in the guidelines is that only the presence of otorrhoea or bilateral hyperaemia should be taken into consideratio. [30-36]

The lesser importance placed on a finding of bilateral hyperaemia $(46.5 \%$ of the paediatricians) compared to unilateral hyperaemia (56.3\%) merits particular attention. This was an unexpected finding, since it has been reported that antibiotics are more beneficial in children under two years of age and in those in whom AOM is bilateral. [33, 37] This suggests that paediatricians in this region need more information on current recommendations regarding the importance of bilateral hyperaemia when diagnosing AOM.

The justification for prescribing antibiotics to children with $\mathrm{AOM}$ is based on a high prevalence of bacteria in middle ear effusion. [38] Bacterial culture and viral isolation from middle ear fluid specimens obtained by tympanocentesis in children with AOM revealed the presence of bacteria in $55 \%$ and a bacterial/viral co-infection in $15 \%$. In recent years, the importance of correctly diagnosing and managing otitis has been emphasized in view of increasing resistance to the principal bacteria involved in its aetiology and of the favourable progression of patients not treated with antibiotics, even in cases of bacterial otitis. [22]

In the present study, the drug of choice for the treatment of otitis was amoxicillin at the standard dose, as indicated by $70.4 \%$ of these paediatricians. This therapy is considered relevant and correct in clinical practice for the treatment of AOM. Justification for the use of amoxicillin is related to its effectiveness against the common pathogens associated with $\mathrm{AOM}$, as well as its safety, low cost, acceptable taste and narrow antimicrobial spectrum. [8-39] According to studies published in the United States, cephalosporins, and even amoxicillin at double the standard dose, are currently the most commonly prescribed drugs; however, the majority of guidelines emphasize this as inappropriate management. $[24,40]$

In children with persistent and severe symptoms of AOM and in cases in which there is no improvement following initial treatment, the clinician may consider changing the antibiotic. [10] Thus, if the child is initially treated with amoxicillin and fails to improve, amoxicillin plus clavulanate may be an option. Another option would be to increase the dose of amoxicillin and to use a second-generation cephalosporin such as cefuroxime or a third-generation cephalosporin such as ceftriaxone $(50 \mathrm{mg} / \mathrm{kg}$ intramuscularly) in a 1- to 3-day treatment course. $[10,41]$ In 
cases in which the patient fails to respond to the first-line treatment, the options used by the paediatricians in the present study were amoxicillin at double the standard dose (40.8\%), amoxicillin at double the standard dose plus clavulanate $(23.9 \%)$, and amoxicillin at the standard dose plus clavulanate $(16.9 \%)$. The options used were considered adequate in the majority of cases and are in accordance with the guidelines. In the great majority of cases $(81.7 \%)$ the antibiotic treatment was continued for 8-10 days. Nevertheless, several studies have recommended shorter courses for children, particularly for infants under two years of age, with 5-7 day courses being recommended. [42-47]

The prescription of analgesics was shown to be practically routine, with $97.1 \%$ of doctors prescribing analgesics in addition to antibiotics for the management of otalgia and other symptoms. This concern with treating pain is in agreement with the AAP recommendations. [24] Indeed, the use of antibiotics does not provide relief from symptoms in the first 24 hours; [32, 42] on the other hand, the use of analgesics effectively provides immediate relief from symptoms.

Children with AOM should be re-evaluated, and $90.1 \%$ of the paediatricians follow this recommendation; however, this practice is often unfeasible in emergency rooms, since the child may not return to the same healthcare service or may not be seen by the same doctor who provided the initial care. This practice is more effective in outpatient visits. Since the present study was conducted exclusively with paediatricians working in emergency rooms, this may have introduced a bias to the study in the sense that the prescription of antibiotics under these circumstances may be greater.

Current guidelines recommend the "wait and see" strategy (watchful waiting) in an attempt to reduce the use of antibiotics. This attitude is supported by evidence on the safety of watchful waiting and delayed prescription of antibiotics to children. [29, 49-53] Furthermore, in a Cochrane review, Venekamp et al. [37] identified studies in which the majority of cases resolved spontaneously, with no complications. In several studies, only around one-third of children initially seen with AOM had to be given rescue antibiotics because their symptoms persisted or became worse, [30, 50, 52-55] suggesting that antibiotic use could be reduced by $65 \%$ in eligible children. Given the high incidence of AOM, this reduction could contribute substantially towards decreasing the adverse events associated with antibiotic use.

The "wait and see" strategy has been emphasized as the best option for these patients [52, 55] with parents/caregivers receiving a prescription for antibiotics at the consultation but being instructed to only begin treatment if the child's condition fails to improve within 2-3 days or to initiate treatment at any moment if symptoms worsen. Nevertheless, this was not a subject of the present study due to the difficulty in implementing "wait-and-see" management in emergency rooms, a setting in which the physician seldom has the opportunity to see the patient again.

Even when antibiotics were prescribed, half the paediatricians in this study recommended that their patients should be re-evaluated 3-5 days after the initial consultation. There is little scientific evidence on the impact of routine reevaluation of children with a diagnosis of AOM. Therefore, re-evaluation should be at the physician's discretion, taking into account the child's age, the intensity of symptoms, recurrence, or a request by the parents/caregivers. [10] Ideally, after commencing treatment with antibiotics, all children should be assessed with regards to clinical response, which is another area in which there is room for improvement in the management of otitis in Brazil.

\section{Conclusions}

The results of the present study underline the importance of the correct management of AOM in childhood, the principal cause of outpatient antibiotic prescriptions in the United States. [29] Although the principal guidelines on the subject were first published more than ten years ago, the results of the present study show that paediatricians working in emergency rooms still need to be provided with more information on the fact that antibiotics should only be prescribed in cases of bilateral hyperaemia or otorrhoea. In addition, we believe that adoption of the "wait and see" strategy, even in emergency rooms, would be an important means of reducing the inadequate prescription of antibiotics in cases of AOM, thus contributing towards reducing bacterial resistance.

\section{Funding}

This research received no specific grant from any funding agency in the public, commercial, or not-for-profit sectors.

\section{Declaration of Conflicting Interests}

The authors declare that there is no conflict of interest.

\section{Authorship Attribution}

Prof. Eduardo Fonseca Lima contributed to the concept and design of the study, analysis and interpretation of data. He drafted the article and revised it critically for important intellectual content he approved the final version to be published.

Prof. Patricia Bezerra contributed to the concept and design of the study, analysis and interpretation of data. She drafted the article and revised it critically for important intellectual content She approved the final version to be published.

Ms. Cazzetta contributed to the concept and design of the study, acquisition of data, analysis and interpretation of data. She drafted the article.

Ms. Cabral contributed to the concept and design of the study, acquisition of data, analysis and interpretation of data. She drafted the article.

Ms. Andrade contributed to the concept and design of the study, acquisition of data, analysis and interpretation of data. 
She drafted the article.

Mr. Pedro Fonseca Lima collaborated on the final review and updating of bibliographic references

\section{References}

[1] Balasundaram N, Phan D, Mazzoni D, Duong E, Sweeny A, Del Mar C, Keijzers G. Acute otitis media in children presenting to the emergency department: Is it diagnosed and managed appropriately? J Paediatr Child Health. 2019 Feb 20

[2] Ovnat Tamir S, Shemesh S, Oron Y, Marom T. Acute otitis media guidelines in selected developed and developing countries: uniformity and diversity. Arch Dis Child. 2017 May; 102 (5): 450-457.

[3] Sih T, Moura R, Caldas S, et al. Prophylaxis for recurrent acute otitis media: A Brazilian study. Int $J$ Pediatr Otorhinolaryngol 1993; 25: 19-24.

[4] Dickson G. Acute otitis media. Prim Care. 2014 Mar; 41 (1):11-8.

[5] Siddiq S, Grainger J. The diagnosis and management of acute otitis media: American Academy of Pediatrics Guidelines 2013. Arch Dis Child Educ Pract Ed. 2015 Aug; 100 (4): 193 7.

[6] Usonis V, Jackowska T, Petraitiene S, Sapala A, Neculau A, Stryjewska I, Devadiga R, Tafalla M, Holl K. Incidence of acute otitis media in children below 6 years of age seen in medical practices in five East European countries. BMC Pediatr. 2016 Jul 26; 16: 10.

[7] Nwokoye NN, Egwari LO, Olubi OO. Occurrence of otitis media in children and assessment of treatment options. J Laryngol Otol. 2015 Aug; 129 (8): 779-83.

[8] Pitaro J, Waissbluth S, Quintal MC, Abela A, Lapointe A. Characteristics of children with refractory acute otitis media treated at the pediatric emergency department. Int $\mathrm{J}$ Pediatr Otorhinolaryngol. 2019 Jan; 116: 173-176.

[9] Toll EC, Nunez DA. Diagnosis and treatment of acute otitis media: review. J Laryngol Otol. 2012 Oct; 126 (10): 976-83.

[10] Chiappini E, Bortone B, Doria M, Landi M, Di Mauro G, Marchisio P. What not to do in acute otitis media: the top five recommendations proposed by the Italian Society of Preventive and Social Pediatrics. Expert Rev Anti Infect Ther. 2017 Oct; 15 (10):897-902.

[11] Kalu SU, Ataya RS, McCormick DP, et al. Clinical spectrum of acute otitis media complicating upper respiratory tract viral infection. Pediatr Infect Dis J 2011; 30: 95-99.

[12] Pichichero ME. First-line treatment of acute otitis media. In: Alper CM, Bluestone CD, Casselbrant ML, et al. (eds). Advanced therapy of otitis media. Hamilton, Ontario: BC Decker, 2004, pp. 32-38.

[13] Gunasekera H, Morris PS, McIntyre P, Craig JC. Management of children with otitis media: a summary of evidence from recent systematic reviews. J Paediatr Child Health. 2009 Oct; 45 (10):554-62.

[14] Vernacchio L, Vezina RM and Mitchell AA. Management of acute otitis media by primary care physicians: trends since the release of the 2004 American Academy of Pediatrics/American Academy of Family Physicians clinical practice guideline. Pediatrics 2007; 120: 281-287.

[15] Coco A, Vernacchio L, Horst M, et al. Management of acute otitis media after publication of the 2004 AAP and AAFP clinical practice guideline. Pediatrics 2010; 125: 214-220.

[16] Marchisio P, Mira E, Klersy C, et al. Medical education and attitudes about acute otitis media guidelines: a survey of Italian pediatricians and otolaryngologists. Pediatr Infect Dis J 2009; 28: 1-4.

[17] Arkins ER and Koehler JM. Use of the observation option and compliance with guidelines in treatment of acute otitis media. Ann Pharmacother 2008; 42: 726-727.

[18] Flores G, Lee $M$, Bauchner $H$, et al. Pediatricians' attitudes, beliefs, and practices regarding clinical practice guidelines: a national survey. Pediatrics 2000; 105 (3 Pt 1): 496-501.

[19] Solén MG and Hermansson A. Novas diretrizes no tratamento da otite media aguda na Suécia; X Manual IAPO de otorrinolaringologia pediátrica,

http://www.iapo.org.br/manuals/x_manual_iapo_pt_22.pdf (2012, accessed 14 April 2014).

[20] Rothman R, Owens T and Simel DL. Does this child have acute otitis media? JAMA 2003; 290: 1633-1640.

[21] Isaacson G. Otoscopic diagnosis of otitis media. Minerva Pediatr. 2016 Dec; 68 (6):470-477. Epub 2016 May 19. Review.

[22] Rettig E, Tunkel DE. Contemporary concepts in management of acute otitis media in children. Otolaryngol Clin North Am. 2014 Oct; 47 (5): 651-72.

[23] Laine MK, Tähtinen PA, Ruuskanen O, et al. Symptoms or symptom-based scores cannot predict acute otitis media at otitis-prone age. Pediatrics 2010; 125: e1154-61.

[24] American Academy of Pediatrics Subcommittee on Management of Acute Otitis Media. Diagnosis and management of acute otitis media. Pediatrics. 2013 Mar; 131 (3):e964-99.

[25] Conselho Federal de Medicina. Conselho Regional de Medicina do Estado de São Paulo. Demografia Médica no Brasil. Dados gerais e descrições de desigualdades. São Paulo: CRM-SP, 2011, 118p.

[26] Lefevre JH, Roupret M, Kerneis S, et al. Career choices of medical students: a national survey of 1780 students. Med Educ 2010; 44: 603-612.

[27] Kiolbassa K, Miksch A, Hermann K, et al. Becoming a general practitioner - which factors have most impact on career choice of medical students? BMC Fam Pract 2011; 12: 25.

[28] Diderichsen S, Johansson EE, Verdonk P, et al. Few gender differences in specialty preferences and motivational factors: a cross-sectional Swedish study on last-year medical students. BMC Med Educ 2013; 13: 39.

[29] Grijalva CG, Nuorti JP and Griffin MR. Antibiotic prescription rates for acute respiratory infections in US ambulatory settings. JAMA 2009; 302: 758-766.

[30] Hoberman A, Paradise JL, Rockette HE, et al. Treatment of acute otitis media in children under 2 years of age. $N$ Engl $J$ Med 2011; 364: 105-115. 
[31] Venekamp RP, Damoiseaux RA, Schilder AG. Acute otitis media in children. BMJ Clin Evid. 2014 Sep 16; 2014.

[32] Pichichero ME, Casey JR, Almudevar A. Reducing the frequency of acute otitis media by individualized care. Pediatr Infect Dis J. 2013 May; 32 (5): 473-8.

[33] Rovers MM, Glasziou P, Appelman CL, et al. Antibiotics for acute otitis media: a meta-analysis with individual patient data. Lancet 2006; 368: 1429-1435.

[34] Schilder AG, Marom T, Bhutta MF, Casselbrant ML, Coates H, Gisselsson-Solén M, Hall AJ, Marchisio P, Ruohola A, Venekamp RP, Mandel EM. Panel 7: Otitis Media: Treatment and Complications. Otolaryngol Head Neck Surg. 2017 Apr; 156 (4_suppl):S88-S105.

[35] Nesbit CE, Powers MC. An evidence-based approach to managing acute otitis media. Pediatr Emerg Med Pract. 2013 Apr; 10 (4): 1-26.

[36] McCormick DP, Chandler SM and Chonmaitree T. Laterality of acute otitis media: different clinical and microbiologic characteristics. Pediatr Infect Dis J 2007; 26: 583-588.

[37] Venekamp RP, Sanders S, Glasziou PP, et al. Antibiotics for acute otitis media in children. Cochrane Database Syst Rev 2013; (1): CD000219.

[38] Heikkinen $\mathrm{T}$ and Chonmaitree T. Importance of respiratory viruses in acute otitis media. Clin Microbiol Rev 2003; 16: 230-241.

[39] Leibovitz E, Greenberg D. Acute otitis media in children: current epidemiology, microbiology, clinical manifestations, and treatment. Chang Gung Med J. 2004 Jul;27 (7):475-88.

[40] Piglansky L, Leibovitz E, Raiz S, et al. Bacteriologic and clinical efficacy of high dose amoxicillin for therapy of acute otitis media in children. Pediatr Infect Dis $J$ 2003; 22: $405-413$.

[41] Leibovitz E, Piglansky L, Raiz S, et al. Bacteriologic and clinical efficacy of one day vs. three-day intramuscular ceftriaxone for treatment of nonresponsive acute otitis media in children. Pediatr Infect Dis J 2000; 19: 1040-1045.

[42] Tähtinen PA, Laine MK, Ruohola A. Prognostic Factors for Treatment Failure in Acute Otitis Media. Pediatrics. 2017 Sep; 140 (3). pii: e20170072.

[43] Paradise JL, Hoberman A, Rockette HE, Shaikh N. Treating acute otitis media in young children: what constitutes success? Pediatr Infect Dis J. 2013 Jul; 32 (7): 745-7.
[44] Hoberman A, Paradise JL, Rockette HE et al. ReducedConcentration Clavulanate for Young Children with Acute Otitis Media. Antimicrob Agents Chemother. 2017 Jun 27; 61 (7).

[45] Cohen R, Levy C, Boucherat M, et al. Five vs. ten days of antibiotic therapy for acute otitis media in young children. Pediatr Infect Dis J 2000; 19: 458-463.

[46] Pichichero ME, Marsocci SM, Murphy ML, et al. A prospective observational study of 5-, 7-, and 10-day antibiotic treatment for acute otitis media. Otolaryngol Head Neck Surg 2001; 124: 381-387.

[47] Kozyrskyj A, Klassen TP, Moffatt M, et al. Short-course antibiotics for acute otitis media. Cochrane Database Syst Rev 2010; (9): CD001095.

[48] American Academy of Pediatrics. Committee on Psychosocial Aspects of Child and Family Health; Task Force on Pain in Infants, Children, and Adolescents. The assessment and management of acute pain in infants, children, and adolescents. Pediatrics 2001; 108: 793-797.

[49] Leung AKC, Wong AHC. Acute Otitis Media in Children. Recent Pat Inflamm Allergy Drug Discov. 2017; 11 (1): 32-40.

[50] McCormick DP, Chonmaitree T, Pittman C, et al. Nonsevere acute otitis media: a clinical trial comparing outcomes of watchful waiting versus immediate antibiotic treatment. Pediatrics 2005; 115: 1455-1465.

[51] Le Saux N, Gaboury I, Baird M, et al. A randomized, doubleblind, placebo-controlled noninferiority trial of amoxicillin for clinically diagnosed acute otitis media in children 6 months to 5 years of age. CMAJ 2005; 172: 335-341.

[52] Spiro DM, Tay KY, Arnold DH, et al. Wait-and-see prescription for the treatment of acute otitis media: a randomized controlled trial. JAMA 2006; 296: 1235-1241.

[53] Marchetti F, Ronfani L, Nibali SC, et al.; Italian Study Group on Acute Otitis Media. Delayed prescription may reduce the use of antibiotics for acute otitis media: a prospective observational study in primary care. Arch Pediatr Adolesc Med 2005; 159: 679-684.

[54] Little P, Gould C, Williamson I, et al. Pragmatic randomised controlled trial of two prescribing strategies for childhood acute otitis media. BMJ 2001; 322: 336-342.

[55] Siegel RM, Kiely M, Bien JP, et al. Treatment of otitis media with observation and a safety-net antibiotic prescription. Pediatrics 2003; 112 (3 Pt 1): 527-531. 